\title{
RESEARCH
}

Open Access

\section{Distal muscle weakness is a common and early feature in long-term enzyme-treated classic infantile Pompe patients}

\author{
J. J. A. van den Dorpel' (D, E. Poelman', L. Harlaar², H. A. van Kooten², L. J. van der Giessen³, P. A. van Doorn²,
}

A. T. van der Ploeg ${ }^{1}$, J. M. P. van den Hout $^{1}$ and N. A. M. E. van der Beek ${ }^{1,2^{*}}$

\begin{abstract}
Background: Enzyme replacement therapy (ERT; alglucosidase alfa) has improved the prospects for patients with classic infantile Pompe disease considerably. However, over time we noticed that many of these children exhibit distal muscle weakness at an early age, which is in contrast to the primarily proximal and axial muscle weakness in patients with late-onset Pompe disease. This was reason to study the prevalence and severity of distal muscle weakness, and the sequence of muscle involvement over time in patients that had learned to walk under ERT.

Methods: In this prospective, single-center cohort study, we studied 16 classic infantile patients. We used video recordings that were made during regular standardized assessments to investigate distal muscle function (active dorsiflexion of the feet during walking; ability to use a pincer grasp/actively extend the fingers) and proximal muscle function (standing up from a supine position; raising the arms above the head).
\end{abstract}

Results: Median age at start of ERT was 3.2 months (0.1-5.8 months), median age at study end was 5.6 years (2.918.2 years). Six patients $(6 / 16,38 \%)$ initially had no evident signs of distal muscle weakness and developed a gait with active dorsiflexion of the feet. The other 10 patients never exhibited active dorsiflexion of the feet during walking. At study-end two patients showed no loss of distal muscle function. A subset of five patients (5/16, 31\%) developed also weakness of the hands, particularly of the extensors of the 3rd and 4th digit.

Conclusions: We found that the majority $(14 / 16,88 \%)$ of patients who had learned to walk exhibited distal muscle weakness of the lower extremities, while a subset $(5 / 16,31 \%)$ also developed weakness of the hands. The distal muscle weakness was often more serious than, and preceded the development of, the proximal muscle weakness.

Keywords: Pompe disease, Glycogen storage disease type II, Enzyme replacement therapy (ERT), Muscle function, Distal muscle weakness

\footnotetext{
*Correspondence: n.beek@erasmusmc.n

${ }^{1}$ Center for Lysosomal and Metabolic Diseases, Department of Pediatrics, Erasmus MC University Medical Center, P.O. Box 2060, Rotterdam 3000, CB, The Netherlands

${ }^{2}$ Center for Lysosomal and Metabolic Diseases, Department of Neurology, Erasmus MC University Medical Center, P.O. Box 2060, Rotterdam 3000, CB, The Netherlands

Full list of author information is available at the end of the article
}

C C The Author(s). 2020 Open Access This article is licensed under a Creative Commons Attribution 4.0 International License, which permits use, sharing, adaptation, distribution and reproduction in any medium or format, as long as you give appropriate credit to the original author(s) and the source, provide a link to the Creative Commons licence, and indicate if changes were made. The images or other third party material in this article are included in the article's Creative Commons licence, unless indicated otherwise in a credit line to the material. If material is not included in the article's Creative Commons licence and your intended use is not permitted by statutory regulation or exceeds the permitted use, you will need to obtain permission directly from the copyright holder. To view a copy of this licence, visit http://creativecommons.org/licenses/by/4.0/. The Creative Commons Public Domain Dedication waiver (http://creativecommons.org/publicdomain/zero/1.0/) applies to the data made available in this article, unless otherwise stated in a credit line to the data. 


\section{Background}

Pompe disease (glycogen storage disease type II, OMIM \#232300) is a rare metabolic disorder caused by the deficiency of acid $\alpha$-glucosidase, leading to lysosomal glycogen accumulation in many tissues, particularly in muscle [1]. Pompe disease encompasses a continuous spectrum, varying from a relentlessly progressive classic infantile phenotype to a less progressive, 'milder' lateonset phenotype $[2,3]$. Classic infantile Pompe disease is characterized by progressive, generalized, muscle weakness manifesting shortly after birth, accompanied by a typical hypertrophic cardiomyopathy. Untreated, patients die before 1 year of age due to cardio-respiratory insufficiency $[4,5]$. Limb-girdle muscle weakness and respiratory dysfunction are the hallmarks of the late-onset phenotype, leading to wheelchair and/or respirator dependency in many patients [2,6-8].

In classic infantile Pompe disease, enzyme-replacement therapy (ERT) with recombinant human acid $\alpha$ glucosidase (rhGAA, alglucosidase alfa) has shown to improve - ventilator-free - survival, reverse the cardiac hypertrophy, and improve patients' muscle function, enabling them to reach previously unmet motor milestones such as standing and walking [9-14]. However, remarkably, also many otherwise very 'good-responding' ERT-treated classic infantile patients exhibit residual muscle weakness. Over the years, we noticed that this muscle weakness was not limited to the proximal muscles - typically seen in the late-onset phenotype in children and adults - but also involved the distal muscles of the feet [15]. This new phenotype comprising proximal and distal muscle weakness, was also noted by several other authors [16-18].

Presently, it is still unclear which percentage of patients develop this distal weakness, at what age this starts to develop, and how it relates to the development of proximal muscle weakness. Furthermore, it is unknown whether this distal weakness is limited to the lower extremities, or involves also the upper extremities, i.e. the hand musculature. Since we have regularly recorded all motor assessments on video from the start of ERT, we had the unique opportunity to study this intriguing question.

\section{Results}

\section{Patients}

Of the 22 patients with classic infantile Pompe disease that were seen in our Center during the study period, 16 (72\%) had learned to walk, and were thus included in this study (Table 1). The most common disease causing variants (www.pompevariantdatabase.nl) were c.del525T (7 patients, 3/7 homozygous) and c.2481+102_2646+ 31del (6 patients, $3 / 6$ homozygous). Median age at start of ERT was 3.2 months (0.1-5.8 months), median age at study end was 5.6 years (2.9-18.2 years). Echocardiography showed hypertrophic cardiomyopathy in all patients pre-ERT, with median left ventricular mass index (LVMI) $210 \mathrm{~g} / \mathrm{m}^{2}$ (range 98-756) and median $\mathrm{z}$ score 19 (range 5-88). During follow-up two patients became ventilator dependent (pat 4 and 11, respective age 2.7 and 2.0 years) after recurrent respiratory infections. Four patients were cross-reactive immunological material (CRIM) negative (pat. 10, 11, 15, 16), one of whom died at the age of 4.4 years due to respiratory failure. The remaining 15 patients were alive at study end.

\section{Video analyses of motor function Lower extremities (Fig. 1a; Table 1)}

Ten patients $(63 \%)$ showed moderate to severe distal muscle weakness from the beginning. As a result, they never developed a walking gait, with active dorsiflexion of the feet resulting in a heelstrike. The best achievement in these patients was a walking pattern with a mid/ forefoot landing. Six patients (37\%) initially had no evident signs of distal muscle weakness: they developed a heelstrike-gait at a median age of 3.0 years (range 2.83.5 years).

With regard to proximal muscle function, nine patients $(56 \%)$ were at any point in time able to rise from a supine position without any visible difficulty or use of external support. The other seven patients (44\%) always showed some signs of proximal muscle weakness, reflected by a Gowers sign or Trendelenburg gait. There were no differences regarding the age at which patients had learned to stand and walk between the patients with or without proximal muscle weakness.

The six patients who initially had no distal muscle weakness also had normal proximal muscle function in the beginning. At the end of the study, four of these patients had reverted to a mid/forefoot landing during walking: three had lost their heelstrike-gait (at age 3.6, 4.0 and 5.0 years) but still had no signs of proximal muscle weakness, while one had developed distal muscle weakness (at age 4.0 years), before also developing proximal muscle weakness (at age 8.1 years). Only two of the 16 patients $(13 \%)$ had no distal weakness at their last assessment at the ages of 2.9 and 4.0 years. They also had no signs of proximal muscle weakness (Table 1).

Of the other 10 patients, at study end, one had normal proximal muscle function but impaired ankle dorsiflexion, four were still able to walk but with evidence of both proximal and distal muscle weakness, while five had lost the ability to stand and walk and had become wheelchair bound due to severe overall muscle weakness.

\section{Dosing and CRIM status}

Only one of the five patients (20\%) who were initially treated with a lower dose of recombinant enzyme 


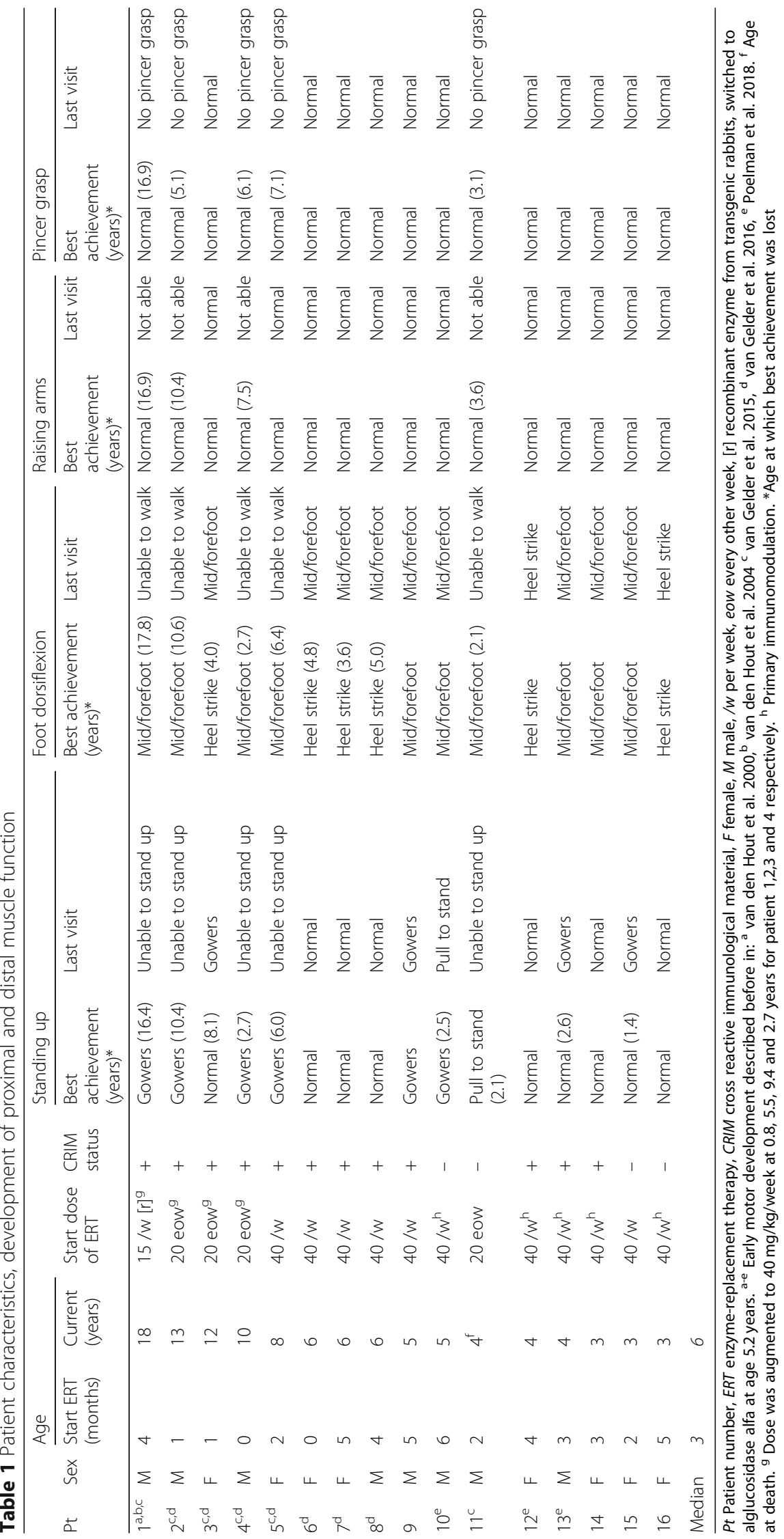




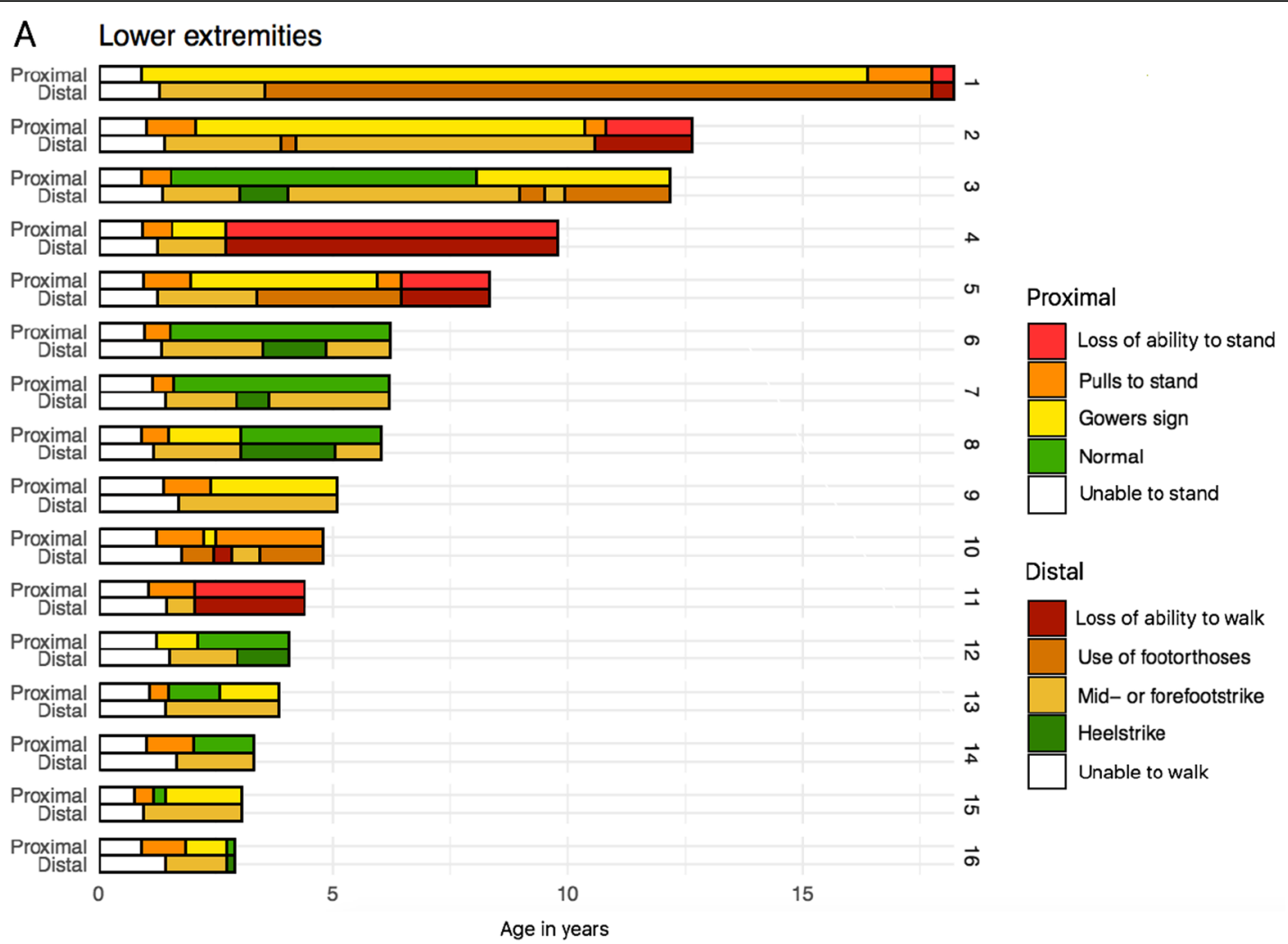

B Upper extremities

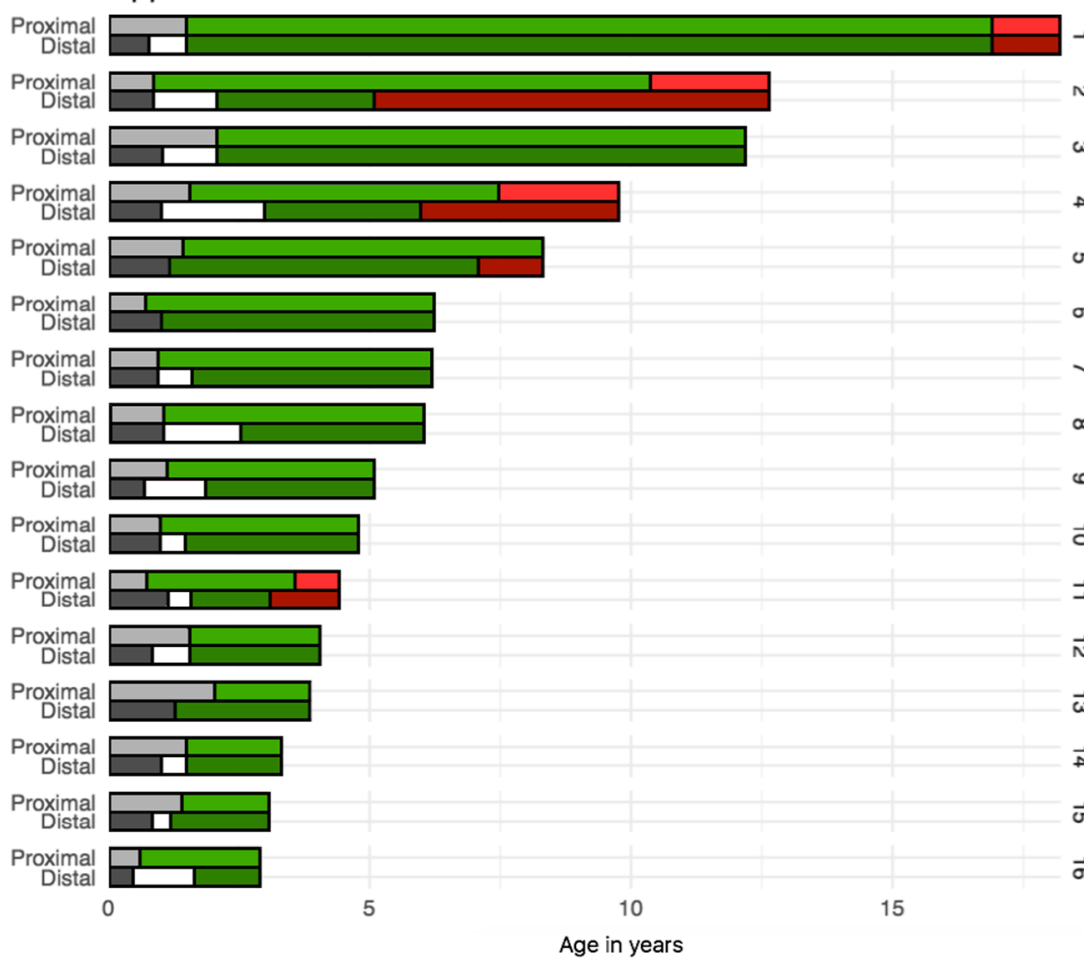

Proximal

$\checkmark$ Loss of ability to raise arms $\infty$ Able to raise arms Not assessed $\overrightarrow{0}$ Distal

$\vec{\square} \square$ Loss of pincergrasp

$\vec{N}$

$\vec{G}$

$\vec{\omega}$

Fig. 1 (See legend on next page.) 
(See figure on previous page.)

Fig. 1 Proximal and distal muscle function in ERT-treated classic infantile Pompe patients. a Proximal and distal muscle function of the lower extremities. Upper column: the ability to come to stand from supine, as a parameter for proximal muscle strength of the legs. Lower column: active dorsiflexion of the feet, reflected in the ability to perform a heel-strike during walking. $\mathbf{b}$ Proximal and distal muscle function of the upper extremities. Upper column: raising arms above head as parameter for proximal muscle function. Lower column: the ability to use a pincer grasp, while performing fine motor tasks

achieved a walking pattern without apparent distal and proximal muscle weakness, while five of the 11 patients (45\%) treated with $40 \mathrm{mg} / \mathrm{kg} /$ week initially showed no muscle weakness of either distal or proximal muscles.

One of the CRIM negative patients $(1 / 4,25 \%$; treated with $40 \mathrm{mg} / \mathrm{kg} /$ week from the start, additional immunomodulation) and 5/12 (42\%) of the CRIM positive patients initially achieved a walking pattern with a normal heelstrike-gait.

\section{Upper extremities (Fig. 1b; Table 1)}

All patients acquired the ability to fully raise their arms above the head and obtained normal fine motor skills, as was evidenced by a normal pincer grasp when picking up small objects (achieved at median age 1.6 years, range 1.0-3.0). During follow-up, three patients developed profound finger extensor weakness mainly of the third and fourth digit (patients 2, 4, and 5; Fig. 2b). These three patients also developed weakness of the upper arms at a later stage. Two other patients also developed some distal muscle weakness reflected by a more crude grip using the whole hand, one of whom had no signs of upper-arm weakness, while in the other patient loss of proximal and distal arm function had coincided with a fracture of the clavicle. The other 11 patients had exhibited no visible impairment of upper-arm and hand function at the end of follow-up. Weakness of the upper extremities was seen only in patients with severe proximal and distal weakness of the lower extremities at an earlier stage.

\section{Other motor features}

\section{Early motor function development}

Patients were able to stand and walk independently at the respective median ages of 1.0 (range $0.8-1.4$ ) and 1.4 years (range 1.0-1.8), which was within the 90th percentile of healthy age-matched controls in $8 / 16,50 \%$ (standing) and 13/16, 81\% (walking) of patients.

Functional motor development, as reflected by their AIMS and BSIDII scores, showed a gradual improvement after start of ERT. At their last BSIDII evaluation, 9/16, $56 \%$ of patients reached an age-equivalent score, reflecting normal development (Data not shown).

\section{Supportive measures}

Due to decreased ankle dorsiflexor strength (Fig. 2a), nine patients eventually needed supportive measures. Seven patients (pat $2-5,7,13,15$ ) used splints at night

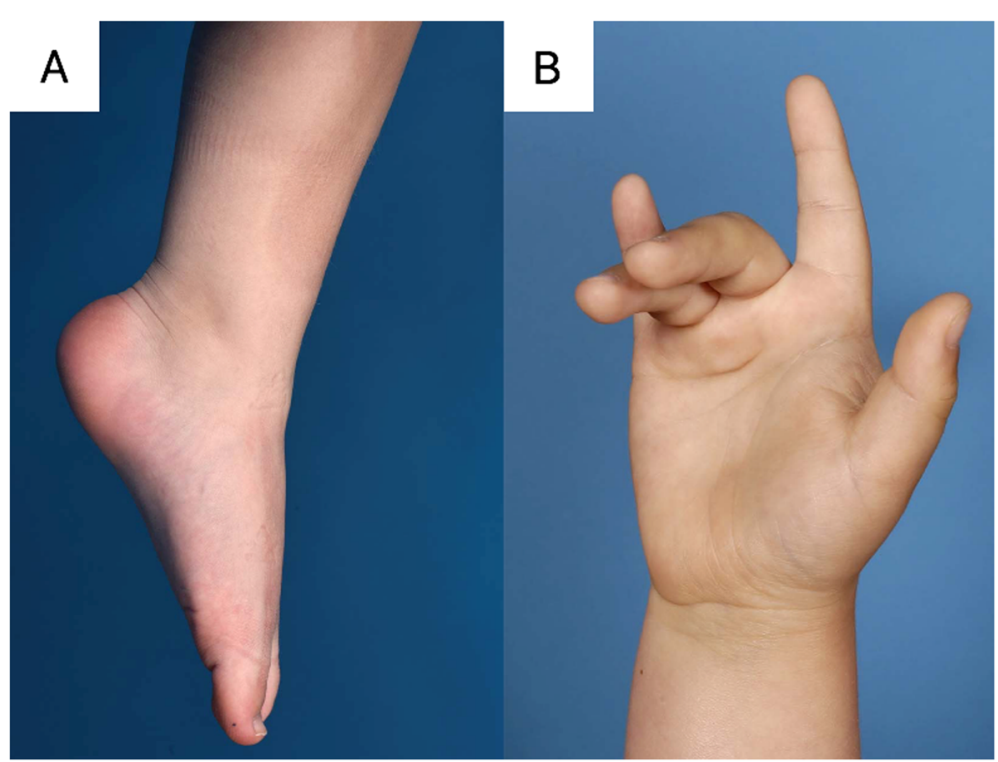

Fig. 2 Distal muscle weakness of the feet and hands in ERT-treated classic infantile Pompe patients. a Severe weakness of foot dorsiflexor muscles, patient was asked to perform active dorsiflexion of the foot. $\mathbf{b}$ Weakness of finger extensor muscles, with characteristic positioning of the $3 r d$ and 4th digit. Picture was taken at maximal finger extension 
to increase ankle mobility and prevent contractures (start use splints between 2.5 and 8.0 years), while five patients (pat $1-3,5,10$ ) used ankle foot orthoses to provide support when walking (start use foot orthoses between 1.8 and 9.0 years). Three patients (pat 2, 3, 5) used both splints and ankle foot orthoses. With these measures, we were able to maintain at least 90 degree ankle dorsiflexion angle in ambulant patients. None of the patients underwent surgery for contractures or other foot deformities. One patient (pat 2) used a hand splint (from age 5.6 years) to support hand function and prevent contractures.

\section{Discussion}

Long-term survival of classic infantile Pompe patients treated with ERT has unveiled a specific phenotype. We studied the occurrence and sequence of involvement of distal and proximal muscle weakness in 16 patients with classic infantile Pompe disease. Although all patients learned to walk, we found that: 1) $88 \%$ of patients developed distal muscle weakness of the lower extremities at any point in time, 2) $31 \%$ of patients developed also weakness of the hands, particularly of the extensors of the 3rd and 4th digit, and 3) patients exhibited a specific pattern of muscle involvement, in which distal muscle weakness of the lower extremities was more serious than and preceded proximal muscle weakness; likewise, weakness of the hands occurred earlier than that of the upper-arms.

Early motor development showed significant improvement after start of ERT, which enabled patients to achieve motor milestones such as standing and walking. Many patients even learned to walk at a normal age compared to their peers.

However, over time, 14 of the 16 patients $(88 \%)$ developed distal weakness of the legs. Importantly, most patients never developed a walking pattern with active foot dorsiflexion $(10 / 16$; $63 \%)$ : six patients (37\%) initially developed a normal heelstrike-gait, four of whom displayed secondary progressive weakness of the distal muscle groups. Only 2 patients - still relatively young (2.9 and 4.3 years) - had a normal heelstrike-gait at the end of follow-up. In our study, all patients above the age of 5 years exhibited distal muscle weakness. From a functional point of view, the distal muscle weakness was in most cases even more severe than the accompanying proximal muscle weakness. Compared to healthy peers, the development of a mature gait with a heelstrike was delayed in all patients ( $\approx 1.5$ years against 3.0 years) [19].

There are only few reports in the literature on the occurrence of distal muscle weakness in long-term treated classic infantile patients. In one retrospective study [17] nine out of 11 treated classic infantile patients, median age 8.0 years (range 5.4-12.0), developed dorsiflexor weakness of the feet. The age at which this distal weakness occurred, or the pattern in which distal and proximal weakness developed, was not reported. Two patients did not show any dorsiflexor weakness (age 5.4 and 8.2 years at study-end). A recent case study reports subacute - over several months - development of dorsiflexor weakness at an older age (6.5 years), attributed to progressive myopathy and possibly also minor peripheral nerve involvement [20].

To our knowledge, weakness of the hand musculature has not been reported in earlier studies. We found that weakness of the upper extremities, including weakness of hand musculature was less prominent and occurred only in patients with severe weakness of lower extremities. Three of the five patients with hand-weakness had a particular positional tendency with flexion of the third and fourth finger. This may result from the fact that third and fourth digit are controlled by only one finger extensor muscle, contrary to the other digits [21].

We found that motor outcome differed between patients. Several factors, including age at start of treatment [9, 10], ERT dose [15] and CRIM status [22, 23], have shown to be of influence on survival and motor outcome. In our study, patients who were treated initially with a lower dose more frequently showed persistent weakness of foot dorsiflexion, compared to patients treated with $40 \mathrm{mg} / \mathrm{kg} /$ week. This better outcome in the higher-dose group is in accordance with our earlier findings [15]. The influence of CRIM status on motor outcome was less apparent. However, it should be noted that the follow-up of the CRIM negative patients was shorter.

The severe and early distal weakness that we have found is discrepant with the predominant limb-girdle and axial weakness seen in children and adults with late-onset Pompe disease. Involvement of dorsiflexor muscles of the feet or specific involvement of the hand musculature does typically not occur in those patients until end-stage disease $[6,7,24,25]$. Only one case of adult Pompe disease has been described, in which weakness of wrist extensor muscles was one of the presenting symptoms [26].

The pathophysiological process underlying the distal muscle weakness is still not fully understood. Several factors might play a role, including extensive involvement of distal muscles in the myopathic process [20, 27], and potential neurogenic involvement due to glycogen storage in the central [28-30] and peripheral nervous system [20,31,32]. Detailed radiological, electrodiagnostic and histological studies in larger numbers of patients are needed to provide a better understanding of the underlying etiology.

Our study had several limitations. Despite a relatively large cohort size of classic infantile patients, the absolute number of subjects is still small. Although we would 
have liked to provide a more quantitative measure of muscle strength, such as manual muscle testing or hand held dynamometry, to strengthen our opinion on the degree of distal versus proximal weakness, these measures are notably unreliable in young children. Additionally, a formal gait analysis studying kinematics of additional muscle joints could have provided more detailed information.

Since we recorded all assessments on video from the beginning, we were able to precisely look at when the distal muscle weakness developed. Loss of ankle dorsiflexion results in an unstable (steppage) gait, which may increase the risk of falling and, consequently, occurrence of fractures. Furthermore, distal muscle weakness may lead to loss of joint mobility resulting in development of contractures. Therefore, awareness and early recognition of distal weakness is important for timely application of supportive measures such as splints and foot orthoses.

\section{Conclusion}

Although many patients now learn to walk under ERTtreatment, the majority develops distal muscle weakness, most prominent of the feet but also of the hand musculature, which is often more serious than, and occurs mostly prior to development of proximal muscle weakness.

\section{Methods}

\section{Patients and study design}

This study is part of a prospective, open-label, cohort study on the long-term effects of enzyme-replacement therapy in classic-infantile Pompe disease, conducted at the center for Lysosomal and Metabolic Diseases of Erasmus MC University Medical Center, the designated center of expertise for Pompe disease in the Netherlands. Patients were included if 1) they had a confirmed diagnosis of classic-infantile Pompe disease, defined as manifesting muscle weakness within 6 months of birth, a hypertrophic cardiomyopathy, and two deleterious disease-causing variants in the acid- $\alpha$-glucosidase gene (GAA), and 2) had learned to walk independently. The earliest data that were used for the purpose of this study are from 1999, database lock was December 31st 2016. Informed consent was obtained from the parents of all patients. From 2009 onward, we treated newly diagnosed patients with recombinant human enzyme (rhGAA; alglucosidase alfa) at a dose of $40 \mathrm{mg} / \mathrm{kg} /$ week from the start. Before that, some patients had initially been treated by recombinant enzyme from transgenic rabbits or with a lower dose of $20 \mathrm{mg} / \mathrm{kg} / 2$ weeks; for all patients initially receiving $20 \mathrm{mg} / \mathrm{kg} / 2$ weeks, between 2009 and 2014 their dose of alglucosidase alfa was increased to $40 \mathrm{mg} / \mathrm{kg} /$ week. Immunomodulation in an ERT-naïve setting with Rituximab (RTX), Methotrexate (MTX) and intravenous immunoglobulins (IVIG) was initiated in 2012, in newly diagnosed patients older than
2 months of age at time of diagnosis. (See for details Poelman et al., 2018) [33].

\section{Procedures \\ Video analyses of motor function}

To investigate the occurrence and severity of distal muscle weakness, and the sequence of muscle involvement, we used video recordings of the regularly performed standardized clinical assessments (AIMS, BSID-II, Quick motor function test (QMFT), Six-minute walk test (6MWT) and timed tests: running $10 \mathrm{~m}$, standing up from supine position (TT)) to construct an overview of the motor development of the patients through time. This resulted in a 4-h summary (= total for all patients) of video material obtained from $122 \mathrm{~h}$ of film, comprising 481 clinical assessments. Video recordings were analyzed every 3 months until the age of 1 year, twice a year between 1 to 3 years of age, and once a year from the age of 3 onwards.

From these video recordings we assessed the following to investigate distal muscle function: (1) active dorsiflexion of the feet during walking resulting in a heel-strike (yes / no) and; (2) weakness of the hands and fingers: ability to use a pincer grasp (yes / no) and being able to actively extend the fingers (yes / no). Proximal muscle weakness was evaluated by assessing (1) coming to stand from a supine position (without difficulty / visible difficulty but without external support (Gowers maneuver) / only with external support (e.g. chair/table) / not able) and (2) raising arms above the head in a straight position (able / not able).

All video material was scored by three independent examiners with experience in pediatrics and/or neuromuscular disorders. If no consensus was reached, results were discussed, and agreed upon in a consensus meeting (JvdD and NvdB).

\section{Other motor features}

Additional investigations to describe overall early motor function development comprised 1) motor milestones (independent sitting, standing, and walking), 2) the Alberta Infant Motor Scale (AIMS), and 3) Bayley Scales of Infant Development II (BSID-II). Established reference values were used to compare patients with age-matched controls [34-36]. Furthermore, we collected information on the timing and type of supportive measures for foot dorsiflexion and prevention of joint contractures, as well as the use of hand splints to support hand functioning.

\section{Statistical analyses}

Due to the small number of patients no comparative statistics were applied. Descriptive statistics, including median and range, were used to summarize demographic and clinical data (SPSS for Windows (version 24, IBM Corp, Armonk, NY). For comparison with healthy peers, established reference values were used. 


\section{Abbreviations}

6MWT: Six minute walking test; AIMS: Alberta Infant Motor scale; BSIDII: Bayley Scales of Infant Development II; CRIM: Cross-reactive immunologic material; ERT: Enzyme replacement therapy; GAA: Acid-a-glucosidase; QMFT: Quick motor function test; rhGAA: Recombinant human alphaglucosidase; TT: Timed tests

\section{Acknowledgements}

The authors would like to thank the patients and their parents for participating in this study. We would like to thank JC van der Meijden for his assistance in preparing figures.

Several of the authors of this publication are members of the European Reference Networks for Hereditary Metabolic Disorders (Metab-ERN) and Rare Neuromuscular Diseases (Euro-NMD)

\section{Authors' contributions}

JvdD participated in the study design, data analyses and data interpretation, and drafted the manuscript. EP, HvK, LH, LvG contributed in data acquisition and revised the manuscript. PvD contributed in data interpretation and revised the manuscript. JvdH, AvdP contributed in data acquisition, data interpretation and revised the manuscript. NvdB conceived the study, participated in its design and data interpretation, revised the manuscript and acted as responsible investigator. We declare that all authors have read and approved the final version of the manuscript, have fulfilled the criteria for authorship, agree with its contents and take full responsibility for the manuscript.

\section{Funding}

Research on Pompe disease at Erasmus MC is financially supported by Prinses Beatrix Spierfonds [project number W.OR16-07]; ZonMw [grant number 152001005]; Tex Net; Sophia Foundation for Medical Research (SSWO) [project number S17-32]; Metakids [project number 2016-063]. This project has received funding from the Ministry of Economic Affairs under TKI-Allowance under the TKI-program Life Sciences \& Health [projectnumber LSHM16008]. This study was also supported in part by Sanofi-Genzyme. Sanofi-Genzyme did not have any influence on the content or design of the study and the drafting and content of the manuscript nor did SanofiGenzyme cover the costs of the study drug. NvdB received a post-doctoral fellowship from the Prinses Beatrix Spierfonds (W.F16-03).

\section{Availability of data and materials}

The dataset is summarized in the figures and table. The raw data used and/ or analyzed during the study are available from the corresponding author on reasonable request. For reasons of privacy, the video material is not publicly available.

\section{Ethics approval and consent to participate}

All procedures followed were in accordance with the ethical standards of the responsible committee on human experimentation (institutional and national) and with the Helsinki Declaration of 1975, as revised in 2000. Informed consent was obtained from all parents of patients for being included in the study. The medical ethical committee of the Erasmus MC approved the study protocol.

\section{Consent for publication}

Not applicable.

\section{Competing interests}

AvdP and HvdH have been advisor for Sanofi-Genzyme, Amicus Therapeutics, Biomarin, Ultragenix, Sarepta, Audentes, and Spark Therapeutics under agreements between these companies and Erasmus MC University Medical Center. NvdB has been advisor for Sanofi-Genzyme, and Amicus Therapeutics under agreements between these companies and Erasmus MC University Medical Center. The other authors declare that they have no conflict of interest. No funding sources had any influence on the content of this manuscript nor provided editorial support.

\section{Author details}

'Center for Lysosomal and Metabolic Diseases, Department of Pediatrics, Erasmus MC University Medical Center, P.O. Box 2060, Rotterdam 3000, CB, The Netherlands. ${ }^{2}$ Center for Lysosomal and Metabolic Diseases, Department of Neurology, Erasmus MC University Medical Center, P.O. Box 2060, Rotterdam 3000, CB, The Netherlands. ${ }^{3}$ Center for Lysosomal and Metabolic Diseases, Department of Pediatric Physiotherapy, Erasmus MC University Medical Center, P.O. Box 2060, Rotterdam 3000, CB, The Netherlands.

\section{Received: 16 April 2020 Accepted: 26 July 2020}

Published online: 14 September 2020

\section{References}

1. Reuser AJ, Hirschhorn R, Kroos MA. Pompe disease: Glycogen storage disease type II, Acid alpha-glucosidase (acid maltase) deficiency. McGraw Hill: The Online Metabolic \& Molecular Bases of Inherited Disease (OMMBID); 2018. [cited 8 October 2018]. Available from: https:// ommbid.mhmedical.com.

2. van der Ploeg AT, Reuser AJ. Pompe's disease. Lancet. 2008;372(9646): $1342-53$.

3. Gungor D, Reuser AJ. How to describe the clinical spectrum in Pompe disease? Am J Med Genet A. 2013;161A(2):399-400.

4. van den Hout HM, Hop W, van Diggelen OP, Smeitink JA, Smit GP, Poll-The $B T$, et al. The natural course of infantile Pompe's disease: 20 original cases compared with 133 cases from the literature. Pediatrics. 2003;112(2):332-40.

5. Kishnani PS, Hwu WL, Mandel H, Nicolino M, Yong F, Corzo D, et al. A retrospective, multinational, multicenter study on the natural history of infantile-onset Pompe disease. J Pediatr. 2006;148(5):671-6.

6. Winkel LP, Hagemans ML, van Doorn PA, Loonen MC, Hop WJ, Reuser AJ, et al. The natural course of non-classic Pompe's disease; a review of 225 published cases. J Neurol. 2005;252(8):875-84.

7. van der Beek NA, de Vries JM, Hagemans ML, Hop WC, Kroos MA, Wokke $\mathrm{JH}$, et al. Clinical features and predictors for disease natural progression in adults with Pompe disease: a nationwide prospective observational study. Orphanet J Rare Dis. 2012;7:88.

8. Van der Beek NA, Hagemans ML, Reuser AJ, Hop WC, Van der Ploeg AT, Van Doorn PA, et al. Rate of disease progression during long-term follow-up of patients with late-onset Pompe disease. Neuromuscul Disord. 2009;19(2):113-7.

9. Van den Hout H, Reuser AJ, Vulto AG, Loonen MC, Cromme-Dijkhuis A, Van der Ploeg AT. Recombinant human alpha-glucosidase from rabbit milk in Pompe patients. Lancet. 2000;356(9227):397-8.

10. Van den Hout JM, Kamphoven JH, Winkel LP, Arts WF, De Klerk JB, Loonen $M C$, et al. Long-term intravenous treatment of Pompe disease with recombinant human alpha-glucosidase from milk. Pediatrics. 2004; 113(5):e448-57.

11. Kishnani PS, Corzo D, Leslie ND, Gruskin D, Van der Ploeg A, Clancy JP, et al. Early treatment with alglucosidase alpha prolongs long-term survival of infants with Pompe disease. Pediatr Res. 2009;66(3):329-35.

12. Kishnani PS, Corzo D, Nicolino M, Byrne B, Mandel H, Hwu WL, et al. Recombinant human acid [alpha]-glucosidase: major clinical benefits in infantile-onset Pompe disease. Neurology. 2007;68(2):99-109.

13. Chakrapani A, Vellodi A, Robinson P, Jones S, Wraith JE. Treatment of infantile Pompe disease with alglucosidase alpha: the UK experience. J Inherit Metab Dis. 2010;33(6):747-50.

14. Hahn A, Praetorius S, Karabul N, Diessel J, Schmidt D, Motz R, et al. Outcome of patients with classical infantile pompe disease receiving enzyme replacement therapy in Germany. JIMD Rep. 2015;20:65-75.

15. van Gelder CM, Poelman E, Plug I, Hoogeveen-Westerveld M, van der Beek N, Reuser AJJ, et al. Effects of a higher dose of alglucosidase alfa on ventilator-free survival and motor outcome in classic infantile Pompe disease: an open-label single-center study. J Inherit Metab Dis. 2016;39(3):383-90

16. Case LE, Beckemeyer AA, Kishnani PS. Infantile Pompe disease on ERT: update on clinical presentation, musculoskeletal management, and exercise considerations. Am J Med Genet C: Semin Med Genet. 2012;160C(1):69-79.

17. Prater SN, Banugaria SG, DeArmey SM, Botha EG, Stege EM, Case LE, et al. The emerging phenotype of long-term survivors with infantile Pompe disease. Genet Med. 2012;14(9):800-10.

18. Muller CW, Jones HN, O'Grady G, Suárez AH, Heller JH, Kishnani PS. Language and speech function in children with infantile Pompe disease. J Pediatr Neurol. 2009; 7(2):147-56.

19. Sutherland DH, Olshen $\mathrm{R}$, Cooper $\mathrm{L}$, Woo SL. The development of mature gait. J Bone Joint Surg Am. 1980;62(3):336-53. 
20. Schanzer A, Gorlach J, Claudi K, Hahn A. Severe distal muscle involvement and mild sensory neuropathy in a boy with infantile onset Pompe disease treated with enzyme replacement therapy for 6 years. Neuromuscul Disord. 2019;29(6):477-82

21. Sobotta J, Paulsen F, Waschke J, Hombach-Klonisch S, Klonisch T. Sobotta atlas of human anatomy, vol. 1. München: Elsevier/Urban \& Fischer; 2013.

22. Kishnani PS, Goldenberg PC, DeArmey SL, Heller J, Benjamin D, Young S, et al. Cross-reactive immunologic material status affects treatment outcomes in Pompe disease infants. Mol Genet Metab. 2010;99(1):26-33.

23. van Gelder CM, Hoogeveen-Westerveld M, Kroos MA, Plug I, van der Ploeg AT, Reuser AJ. Enzyme therapy and immune response in relation to CRIM status: the Dutch experience in classic infantile Pompe disease. J Inherit Metab Dis. 2015;38(2):305-14.

24. Muller-Felber W, Horvath R, Gempel K, Podskarbi T, Shin Y, Pongratz D, et al. Late onset Pompe disease: clinical and neurophysiological spectrum of 38 patients including long-term follow-up in 18 patients. Neuromuscul Disord. 2007;17(9-10):698-706.

25. van der Meijden JC, Kruijshaar ME, Harlaar L, Rizopoulos D, van der Beek N, van der Ploeg AT. Long-term follow-up of 17 patients with childhood Pompe disease treated with enzyme replacement therapy. J Inherit Metab Dis. 2018:41:1205-14.

26. Montagnese F, Barca E, Musumeci O, Mondello S, Migliorato A, Ciranni A, et al. Clinical and molecular aspects of 30 patients with late-onset Pompe disease (LOPD): unusual features and response to treatment. J Neurol. 2015; 262(4):968-78.

27. Pichiecchio A, Rossi M, Cinnante C, Colafati GS, De Icco R, Parini R, et al. Muscle MRI of classic infantile pompe patients: fatty substitution and edema-like changes. Muscle Nerve. 2017:55(6):841-8.

28. Mancall EL, Aponte GE, Berry RG. Pompe's disease (diffuse Glycogenosis) with neuronal storage. J Neuropathol Exp Neurol. 1965;24:85-96.

29. Gambetti P, DiMauro S, Baker L. Nervous system in Pompe's disease. Ultrastructure and biochemistry. J Neuropathol Exp Neurol. 1971;30(3):412-30.

30. Martin JJ, de Barsy T, van Hoof F, Palladini G. Pompe's disease: an inborn lysosomal disorder with storage of glycogen. A study of brain and striated muscle. Acta Neuropathol. 1973;23(3):229-44.

31. Burrow TA, Bailey LA, Kinnett DG, Hopkin RJ. Acute progression of neuromuscular findings in infantile Pompe disease. Pediatr Neurol. 2010; 42(6):455-8

32. Hobson-Webb LD, Dearmey S, Kishnani PS. The clinical and electrodiagnostic characteristics of Pompe disease with post-enzyme replacement therapy findings. Clin Neurophysiol. 2011;122(11):2312-7.

33. Poelman $E$, Hoogeveen-Westerveld M, Kroos-de Haan MA, van den Hout JMP, Bronsema KJ, van de Merbel NC, et al. High sustained antibody titers in patients with classic infantile Pompe disease following immunomodulation at start of enzyme replacement therapy. J Pediatr. 2018;195:236-43 e3.

34. Van der Meulen BF, Ruiter SAJ, Spelberg HCL, Smrkovsky M. Bayley scales of infant development-II. Dutch version. Lisse: Swets; 2002.

35. Bayley N. Manual for the Bayley scales of infant development. San Antonio: The Psychological Corporation; 1993.

36. Laurent de Angulo MS. Ontwikkelingsonderzoek in de jeugdgezondheidszorg : het Van Wiechenonderzoek: de Baecke-Fassaert motoriektest. Assen: Koninklijke Van Gorcum; 2008.

\section{Publisher's Note}

Springer Nature remains neutral with regard to jurisdictional claims in published maps and institutional affiliations.

\section{Ready to submit your research? Choose BMC and benefit from:}

- fast, convenient online submission

- thorough peer review by experienced researchers in your field

- rapid publication on acceptance

- support for research data, including large and complex data types

- gold Open Access which fosters wider collaboration and increased citations

- maximum visibility for your research: over $100 \mathrm{M}$ website views per year

At $\mathrm{BMC}$, research is always in progress.

Learn more biomedcentral.com/submissions 